\title{
Urgences
}

\section{Nom commun. No comment.}

\section{Elsie L. Vandelvort}

Numéro 20, mai 1988

Appellation contrôlée

URI : https://id.erudit.org/iderudit/025480ar

DOI : https://doi.org/10.7202/025480ar

Aller au sommaire du numéro

Éditeur(s)

Urgences

ISSN

0226-9554 (imprimé)

1927-3924 (numérique)

Découvrir la revue

Citer ce document

Vandelvort, E. L. (1988). Nom commun. No comment. Urgences, (20), 45-46. https://doi.org/10.7202/025480ar

Ce document est protégé par la loi sur le droit d'auteur. L'utilisation des services d'Érudit (y compris la reproduction) est assujettie à sa politique d'utilisation que vous pouvez consulter en ligne.

https://apropos.erudit.org/fr/usagers/politique-dutilisation/
Cet article est diffusé et préservé par Érudit.

Érudit est un consortium interuniversitaire sans but lucratif composé de l'Université de Montréal, l'Université Laval et l'Université du Québec à Montréal. Il a pour mission la promotion et la valorisation de la recherche. https://www.erudit.org/fr/ 


\title{
ELSIE L. VANDELVORT \\ Nom commun. No comment.
}

\begin{abstract}
à R.D.
La communauté des anonymes et des solitudes, unie par une douleur, un manque, un désir de parole [...] dont on ne peut dire qu'il soit tout à fait irréel*.
\end{abstract}

- Savez-vous? Il faudrait que les livres n'aient plus de noms, jamais' ${ }^{1}$. ll y a trop de signatures, partout. Les gens passent leur temps à signer, tout, partout [...] chaque fois qu'ils ont une idée, en parlant, au café, ils s'arrêtent un peu et ils vous regardent avec des yeux brillants, et ils SIGNENT! [...] Ils ont des armures tellement solides, et des haches, des quantités de haches. ${ }^{2}$

- l'anonymat serait la condition paradoxale qu'un tyran de l'esprit imposerait aux Lettres ${ }^{3}$

- Avoir un nom, c'était très important sans doute au temps de la bourgeoisie balzacienne

- Peut-être n'est-ce pas un progrès, mais il est certain que l'époque actuelle est plutôt celle du numéro matricule ${ }^{4}$

- Jean Duval était-il un pseudonyme [?]

- oui [,] son vrai nom c'est Martin Coulon ${ }^{5}$

- Baudelaire aurait [-il] pu s'appeler Poulet-Malassis comme son éditeur [?]

- Non [...] ça ne passe pas. Pas plus que Michelet portant le nom de son collègue Crétineau-Joly. Ou Arthur Rimbaud s'appelant comme son beau-frère Paterne Berrichon. (...) Il y a des noms qui se prêtent à la postérité et d'autres qui l'interdisent.

— Le coup de maître [...], c'est Stendhal qui l'a réussi. Il a incité la postérité à exploiter son nom et son pseudonyme ${ }^{6}$

- l'auteur n'est qu'un détail à peu près inutile

[...] le fantasme nécessaire à tout dogme de l'expression

- [...] avec les détails oiseux de sa psychologie et le culte persistant de son nom, l'auteur est (juste une) fiction propre à se déployer comme un écran devant les problèmes de travail ${ }^{8}$

- en effet, j'utilise des noms d'emprunt, un peu comme vous ${ }^{9}$. Mon nom [...] n'existe plus ${ }^{10}$. J'aimerais que le prochain soit $\mathrm{Ed} \mathrm{Word}^{11}$. Je suis de ces personnes qui n'attirent pas l'oeil ${ }^{12}$.

- le texte c'est ce qui se multiplie à l'inverse du représentatif de tout cabotinage $^{13}$ (...) plus vaste est la profusion textuelle, plus elle dévaste la projection individuelle ${ }^{14}$

- en fait ce qui compte ce sont les détails physiques sur lesquels le roman met l'accent, les ongles rongés de Bronko, le duvet sur les joues de Bridg ${ }^{15}$ 
- il n'y a qu'une personne qui pourrait nous dire la vérité: l'auteur ${ }^{16}$

- Monsieur Martin [,] [...] l'auteur, nous le savons assez, accentue l'identité du texte. [Ce qu'il faudrait invoquer c'est] le texte allogène (...) le texte allogène compose, quitte à se mettre hors-la-loi, comme une inadmissible conjugaison de plusieurs écrivains méconnus. D'où [...] une somme de diverses invitations opiniâtres ${ }^{17}$ - Vous voulez dire qu'un collage qui préserverait de toute mise à nu et inscrirait, énigmatique, des noms à titre divers au who is who des sans histoires serait tout aussi éperdument anonyme que Joseph $\mathrm{K}$. et $C^{k}$ ?

- Ne confondons pas l'anonyme (un don par exemple) et l'innommable... Il s'agit de méthode, et il se trouve que le dialogue est une forme qui privilégie l'insertion des [...] tout autant que leur absence $^{18}$.

\section{Dans l'ordre d'apparition:}

* Pierre Nepveu: al'ère de la sensation vraie», dans Estuaire, \# 47, p. 17.

1 Jean-Marie-Gustave Le Clézio: Le liure des fuites; Gallimard, p. 115.

2 Jean-Marie-Gustave Le Clézio: La guerre, Gallimard, p. 163.

3 Paul Valéry: Variétés, «Fragments des mémoires d'un poème», cité par Jean Ricardou, in Pour une thérie du Nouveau Roman, Seuil, p. 68.

4 Alain Robbe-Grillet: Pour un nouveau roman, Minuit, p. 28.

5 Robert Pinget: L'inquisitoire, Minuit, p. 62.

6 Jacques Laurent: Les sous-ensembles flous, Grasset, p. 164-165.

7 Paul Valéry: «Dialogue de l'arbre», in Pour une théorie... op. cité.

8 Jean Ricardou: op. cité.

9 Jean Ricardou: Le théatre des métamorphoses, Seuil, p. 65.

10 Jacques Brault: Trois fois passera, Le Noroit, p. 81.

11 Jean Ricardou: op. cité, Seuil, p. 51.

12 Italo Calvino: Si par une nuit d'hiver un voyageur... Gallimard Poche, p. 19.

13 Jean Ricardou: op. cité, p. 50.

14 Jean Ricardou: op. cité, p. 59.

15 Italo Calvino: op. cité, p. 40.

16 Italo Calvino: op. cité, p. 171.

17 Jean Ricardou: op. cité, p. 65.

18 Auteur inconnu, illisible. 